 \\ 三INTERF SPACC8
}

\section{INTERFACES DO RURAL E DO URBANO NA CIDADE DE BARCARENA, AMAZÔNIA PARAENSE}

\author{
RURAL AND URBAN INTERFACES IN THE CITY OF \\ BARCARENA, PARAENSE AMAZON
}

\section{INTERFACES RURALES ET URBAINES DANS LA VILLE DE BARCARENA, AMAZONIE PARAENSE}

\section{Jovenildo Cardoso Rodrigues}

Doutor em Geografia pela Universidade Estadual Paulista - UNESP/Presidente Prudente/SP Professor do Programa de Pós-Graduação em Geografia da Universidade Federal do Pará PPGEO/ UFPA.

jovenildo@ufpa.br / http://orcid.org/0000-0002-5650-1168

\section{Rodrigo Luciano Macedo Machado}

Mestrando em Geografia pela Universidade Federal do Pará - PPGEO/UFPA. rodrigommluciano@hotmail.com / http://orcid.org/0000-0002-8950-0313

\section{Luciano Rocha da Penha}

Doutorando em Geografia pela Universidade Federal do Pará - PPGEO/UFPA. Professor e

Pesquisador da Universidade Federal do Maranhão - UFMA/Câmpus de Grajaú. penha.luciano@ufma.br / http:// orcid.org/0000-0001-5717-1618

\section{Adolfo Oliveira Neto}

Doutor em Geografia pela Universidade Estadual Paulista - UNESP/Presidente Prudente/SP. Docente da Faculdade de Geografia e Cartografia e do Programa de Pós-Graduação em Geografia da Universidade Federal do Pará - UFPA. Sócio Efetivo do Instituto Histórico e Geográfico do Pará (IHGP). adolfo.oliveira.neto@gmail.com / http://orcid.org/0000-0003-0420-6295

Recebido para avaliação em 30/01/2020; Aceito para publicação em 10/03/2020.

\section{RESUMO}

As cidades brasileiras vêm passando por transformações aceleradas como resultado de determinações vinculadas ao avanço dos processos de urbanização do território, estruturação de cidades, conformando um mosaico complexo, diverso e contraditório de múltiplos territórios e territorialidades urbano-rurais. Em escala local, a cidade de Barcarena revela-se como espaço de intensas metamorfoses socioespaciais, enquanto produto de ações do Estado e de novos agentes econômicos na constituição da urbanização extensiva do território paraense, com reverberações nas relações e interfaces do rural e do urbano na referida cidade. O presente artigo objetiva analisar as relações e interfaces do rural e do urbano no município e na cidade de Barcarena, Amazônia paraense, a partir dos anos 2000. Como procedimento metodológico, realizamos levantamento bibliográfico e documental, produção cartográfica, registros fotográficos e entrevistas semiestruturadas com agentes do poder público municipal e moradores de áreas rurais e urbanas. Defendemos a ideia de que o rural e o urbano em Barcarena encontram-se amalgamados enquanto processos que revelam coexistências, resistências, bem como, interfaces imbricadas da relação ruralurbano em Barcarena, conformando um mosaico articulado e conflituoso de espacialidades urbanorurais. 
|Jovenildo Cardoso Rodrigues | Rodrigo Luciano Macedo Machado | Luciano Rocha da Penha| | Adolfo Oliveira Neto |

Palavras-chave: Rural-Urbano; Cidade; Amazônia; Barcarena.

\begin{abstract}
Brazilian cities have been undergoing accelerated transformations as a result of determinations linked to the advance of the processes of urbanization of territory, structuring of cities, forming a complex, diverse and contradictory mosaic of multiple territories and urban-rural territorialities. On a local scale, the city of Barcarena reveals itself as a space of intense socio-spatial metamorphoses, as a product of state actions and new economic agents in the constitution of extensive urbanization of Pará territory, with reverberations in the relations and interfaces of rural and urban in that city. This article aims at analyzing the relations and interfaces of rural and urban in the municipality and city of Barcarena, in the Amazon region of Pará, starting in the 2000s. As a methodological procedure, we conducted bibliographic and documentary surveys, cartographic production, photographic records and semi-structured interviews with municipal government agents and residents of rural and urban areas. We defend the idea that the rural and the urban in Barcarena are amalgamated as processes that reveal coexistence, resistance, as well as, imbricated interfaces of the rural-urban relationship in Barcarena, forming an articulated and conflicting mosaic of urban-rural spatialities.
\end{abstract}

Keywords: Rural-Urban; City; Amazon; Barcarena.

\title{
RÉSUMÉ
}

Les villes brésiliennes ont connu des transformations accélérées suite à des déterminations liées à l'avancée des processus d'urbanisation, à la structuration des villes, formant une mosaïque complexe, diverse et contradictoire de multiples territoires et territorialités urbaines-rurales. $\grave{A}$ l'échelle locale, la ville de Barcarena se révèle être un espace d'intenses métamorphoses sociospatiales, produit des actions de l'État et des nouveaux agents économiques dans la constitution d'une urbanisation extensive du territoire du Pará, avec des répercussions sur les relations et les interfaces entre le rural et l'urbain dans cette ville. Le présent article vise à analyser les relations et les interfaces entre le rural et l'urbain dans la municipalité et la ville de Barcarena, dans la région amazonienne du Pará, à partir des années 2000. Comme procédure méthodologique, nous avons mené des enquêtes bibliographiques et documentaires, des productions cartographiques, des enregistrements photographiques et des entretiens semi-structurés avec des agents de l'administration municipale et des résidents des zones rurales et urbaines. Nous défendons l'idée que le rural et l'urbain à Barcarena sont amalgamés en tant que processus qui révèlent la coexistence, la résistance, ainsi que les interfaces imbriquées de la relation rural-urbain à Barcarena, formant une mosaïque articulée et conflictuelle de spatialités urbaines-rurales.

Mots-clés: Rural-Urban; Ville; Amazone; Barcarena.

\section{INTRODUÇÃO}

As cidades brasileiras vêm apresentando dinâmicas territoriais aceleradas no início do século XXI, como resultado de determinações vinculadas ao avanço dos processos de urbanização do território, estruturação de cidades, conformando um mosaico complexo, diverso e contraditório de múltiplos territórios e territorialidades urbanas (MONTE-MÓR, 2006; RODRIGUES; RODRIGUES, 2020).

$\mathrm{Na}$ escala do território paraense, as duas primeiras décadas do século XXI vêm sendo marcadas por dinâmicas territoriais vinculadas a impulsos da produção capitalista do espaço, expressas pelo forte avanço do agronegócio, ações estruturantes do Estado na 
|Jovenildo Cardoso Rodrigues | Rodrigo Luciano Macedo Machado | Luciano Rocha da Penha| |Adolfo Oliveira Neto |

indução da urbanização extensiva do território, bem como, por reconfigurações e mutações nos espaços urbanos e rurais como resultados de conflitualidades, espacialidades e territorialidades diversas e desiguais (PORTO-GONÇALVES, 2017; RODRIGUES; SOBREIRO FILHO; OLIVEIRA NETO, 2018).

Em escala local, a cidade de Barcarena, localizada no território paraense revela-se como espaço de intensas metamorfoses socioespaciais, enquanto produto de ações do Estado, na estruturação do território, de novos agentes econômicos que passaram a se territorializar na escala do município, bem como, de agentes sociais excluídos, com reverberações nas relações e interfaces do rural e do urbano na referida cidade (NAHUM, 2008).

Neste sentido, a pesquisa aqui apresentada tem como objeto de estudo a relação rural-urbano, e como recorte territorial o espaço da cidade de Barcarena. Tal escolha vincula-se à necessidade de entendermos as rápidas transformações na escala desta cidade paraense, decorrente de sua condição de cidade portuária, industrial, rodoviária, ribeirinha, cujos nexos de modernização vêm interferindo nos modos de vida, tanto em espaços rurais, quanto em espaços urbanos. Neste sentido, o presente artigo objetiva analisar as relações e interfaces do rural e do urbano no município e na cidade de Barcarena, Amazônia paraense, a partir dos anos 2000.

O método dialético constituiu instrumento para análise do movimento de contradições da realidade social ${ }^{1}$. Como procedimento metodológico, realizamos levantamento e análise bibliográfica e documental de artigos, dissertações, teses, livros que abordaram a referida temática objeto de estudo. Por sua vez, realizamos a produção cartográfica, além de registros fotográficos em determinados espaços da cidade de maneira a identificar algumas práticas espaciais vinculadas à questão da interface e das relações rural-urbano. Por último, mas não menos importante, realizamos entrevistas semiestruturadas com agentes do poder público municipal e moradores de áreas rurais e urbanas.

Defendemos a ideia de que o rural e o urbano em Barcarena encontram-se amalgamados enquanto processos que revelam coexistências, resistências, bem como, interfaces imbricadas da relação rural-urbano em Barcarena, conformando um mosaico articulado e conflituoso de espacialidades urbano-rurais diversas e desiguais.

O referido artigo encontra-se subdividido em quatro momentos. Tais momentos representam esforço no sentido explicativo e analítico da pesquisa, encontrando-se

1 Para Sposito (2004), o método dialético consiste em perspectiva teórica que possibilita análise das contradições vinculadas à realidade social. 
| Interfaces do rural e do urbano na cidade de Barcarena, Amazônia paraense |

|Jovenildo Cardoso Rodrigues | Rodrigo Luciano Macedo Machado | Luciano Rocha da Penha| |Adolfo Oliveira Neto |

articulados e complementares em suas relações e mediações. O primeiro momento consiste nesta introdução ao debate, momento no qual apresentamos a temática de pesquisa, problematizamos a proposta analítica e apresentamos o caminho teórico-metodológico. No segundo momento, realizamos uma breve revisitação aos conceitos de rural e urbano, campo e cidade, para sinalizar o caminho analítico e situar o leitor no debate empírico. No terceiro momento, trouxemos uma breve caracterização histórico-geográfica da cidade de Barcarena, atentando para algumas dinâmicas econômicas, demográficas e espaciais. No quarto momento, abordamos algumas perspectivas e interfaces do rural e do urbano a partir de narrativas do poder público e de moradores do lugar. Finalizamos com as considerações finais, momento em que retomamos o debate para pensar as universalidades, particularidades e singularidades do rural e do urbano em Barcarena no início do século XXI.

\section{O RURAL E O URBANO, O CAMPO E A CIDADE}

A compreensão sobre as relações rural-urbano requer o estabelecimento de aproximações conceituais e analíticas sobre o respectivo tema, parafraseando Lencioni (2008), para quem os conceitos só existem a partir de uma definição ou de um conjunto de definições, concebidas enquanto constructo resultante da interação entre elementos teóricos e a realidade empírica em realização.

Para Monte-Mór (2006), o urbano sinaliza para a necessidade de pensarmos as sociabilidades e relações dialéticas entre campo e cidade ao longo do tempo históricogeográfico. A vida urbana passou por várias transformações que significaram o mundo da vida urbano-industrial, seja por sua influência indireta na articulação de outras cidades e regiões, seja por centralidades urbanas e industriais, ou através de lugares e serviços em regiões agrárias (MONTE-MÓR, 2006).

Sposito (2004) ressalta que na urbanização contemporânea mescla-se superposição ou maior grau de articulação entre o urbano e o rural, muitas vezes expressos por menor distinção entre o campo e a cidade, não sendo indicadores de uma superação do modo capitalista de produção. Nesse sentido, o contexto do urbano não deve ser relacionado exclusivamente à cidade, mas também deve abranger as dinâmicas industriais e o processo de produção, bem como a reprodução das relações de produção capitalistas (SPOSITO, 2004).

Lefebvre (1969) afirma que a urbanização tende a apagar a distinção cidade-campo, como resultado da maneira contraditória como se desenvolve os valores de troca, fato que 
|Jovenildo Cardoso Rodrigues | Rodrigo Luciano Macedo Machado | Luciano Rocha da Penha| |Adolfo Oliveira Neto |

vem contribuindo para a permanência de "ilhas de ruralidade" em razão da implosão/explosão da cidade. Mas como estas ruralidades e urbanidades estão correlacionadas nos tempos de hoje? Ainda há uma nítida divisão entre estas dinâmicas? A esse respeito, Kieling e Silveira (2015) afirmam que:

Comumente, quando as expressões urbanidade e ruralidade são utilizadas, estão carregadas de um significado contraditório, em que a primeira vincula-se a ideia de civilidade, fineza, modernidade e a segunda traz implícita uma conotação pejorativa, associando ideias de atraso, indelicadeza, rusticidade, entre outras, até mesmo a profissão de agricultor traz na sua bagagem e peso de uma cultura que a interpretou ao longo do tempo como uma profissão menor ou inferior (KIELING; SILVEIRA, 2015, p. 135).

Logo, quando abordamos estes aspectos distintos precisamos ressaltar que esta relação é complexa, e as ruralidades e urbanidades são elementos que ultrapassam barreiras a todo momento. Dessa maneira, não há uma sobreposição do urbano frente à perspectiva rural, entretanto, ocorre a transformação cada vez mais acelerada de novas ruralidades, impulsionadas pelas políticas hegemônicas e de reprodução do capital. No que se refere ao rural, a partir desta análise, ressaltamos como esta relação - urbano e rural - se interliga às condições preexistentes na Amazônia. A esse respeito, Rodrigues, Sobreiro Filho e Oliveira Neto (2018) compreendem que:

[...] a condição rural não está relacionada a um suposto "atraso" nos níveis de desenvolvimento da técnica e da modernização do território amazônico, mas ao processo de colonização que se impôs no âmbito da incorporação da Amazônia no contexto de mundialização do capital, cujas contradições estão expressas nas paisagens e configurações territoriais urbanas e rurais da Amazônia brasileira, a partir da reprodução de assentamentos urbanos precários, conflitos fundiários, concentração de terra, violência no campo e na cidade, segregação socioespacial, condições de vida precária em espaços urbanos e rurais (RODRIGUES; SOBREIRO FILHO; OLIVEIRA NETO, 2018, p. 263).

As especificidades e particularidades da relação urbano e rural na Amazônia devem ser consideradas a partir de três elementos centrais em movimento, conforme Rodrigues, Sobreiro Filho e Oliveira Neto (2018) destacam:

O rural-urbano necessita ser compreendido como relação, em razão da interpenetração, imbricamento e dialeticidade dos referidos processos. Por sua vez, o rural-urbano necessita ser apreendido também enquanto condição espacial, diante da necessidade de pensarmos a reprodução das relações sociais de produção no tempo histórico-geográfico. Ademais, mas não menos importante, o rural-urbano deve ser entendido como contradição, posto que tais processos não estão isentos da interferência das determinações inerentes ao desenvolvimento geográfico desigual e suas manifestações socioespaciais em escalas metropolitanas e não metropolitanas, no rural e no urbano como desigualdade socioespacial, processo este resultante da implosão/explosão da 
| Interfaces do rural e do urbano na cidade de Barcarena, Amazônia paraense |

|Jovenildo Cardoso Rodrigues | Rodrigo Luciano Macedo Machado | Luciano Rocha da Penha| |Adolfo Oliveira Neto |

cidade (RODRIGUES; SOBREIRO FILHO; OLIVEIRA NETO, 2018, p. 263).

Considerando tal perspectiva, o rural-urbano constitui a um só tempo, processos e pares dialéticos indissociáveis, solidários e contraditórios, realizando-se enquanto necessidade e possibilidade para a análise de dinâmicas territoriais urbano-rurais, inerentes à condição espacial contemporânea brasileira (CARLOS, 2013), notadamente marcada por um mosaico de espacialidades e territorialidades complexas, múltiplas, diversas, bem como, por lógicas, racionalidades, contrarracionalidades, lutas urbanas e rurais, resistências de comunidades em defesa de seus territórios, acelerada territorialização do capital, tanto em espaços rurais, quanto em áreas urbanas da Amazônia paraense.

\section{BREVE CARACTERIZAÇÃO HISTÓRICO-GEOGRÁFICA DA CIDADE DE BARCARENA}

O território do município e da cidade de Barcarena foi inicialmente habitado pelos índios Aruãs, os mesmos que, durante o período do Brasil colonial, foram "catequizados" pelos padres jesuítas (RODRIGUES, 2011). O respectivo território foi elevado à categoria de freguesia, cujo nome era São Francisco Xavier de Barcarena, no ano de 1758 (RODRIGUES, 2011). Naquelas circunstâncias histórico-geográficas, as formas de usos e apropriação do território barcarenense estavam fortemente atreladas às dinâmicas das redes de rios, que ditavam o tempo e o ritmo da natureza, enquanto elemento predominante na constituição de ruralidades nas relações socioespaciais ribeirinhas.

Conforme Rodrigues (2011), no período anterior a 1709, as terras do Município de Barcarena, antes haviam recebido o nome de Fazenda Geribirié e, posteriormente, ficaram conhecidas como "Missão Geribirié". A partir do final do século XIX ocorreu a criação da Lei Estadual no 494, de 10 de maio de 1897, incorrendo a instalação do distrito de Barcarena, em 2 de janeiro de 1898 (RODRIGUES, 2011). Por sua vez, a partir da promulgação do Decreto-Lei Estadual no 4.505, de 30 de dezembro de 1943, Barcarena passou a ser reconhecida como Município do Estado do Pará, estabelecendo seus limites e localização (Figura 01).

A década de 1970 constitui período de muitas transformações no território brasileiro, como resultado de ações do governo federal, no sentido do ordenamento territorial dos complexos regionais brasileiros, de maneira a adequá-los ao contexto de incorporação de suas economias nas dinâmicas da globalização (NAHUM, 2011). A esse respeito, Nahum discorre que: 
|Jovenildo Cardoso Rodrigues | Rodrigo Luciano Macedo Machado | Luciano Rocha da Penha| |Adolfo Oliveira Neto |

O governo federal ofereceu aos empreendedores da Albrás/Alunorte uma série de incentivos visando atrair para a região a planta industrial de alumínio. A energia foi um dos principais atrativos, não só pela quantidade, que a produção de alumínio demanda, como pelo preço e pela forma como este insumo foi ofertado. Em setembro de 1973 a ELETRONORTE - Centrais Elétricas do Norte do Brasil S/A - foi criada para ampliar a exploração do potencial energético da região e construir um grande sistema de engenharia, a Usina Hidrelétrica de Tucuruí, fornecedora de energia aos Grandes Projetos de produção mínerometalúrgicos (NAHUM, 2011, p. 67-68).

Ainda sobre a importância exercida pelo governo brasileiro na estruturação do território amazônico, Nahum afirma que:

O Estado brasileiro, além da Usina Hidrelétrica de Tucuruí, ainda custeou e construiu todos os sistemas de engenharia de transporte no setor hidroviário e rodoviário, um porto graneleiro e de carga geral para navios de grande calado, além do núcleo urbano de Vila dos Cabanos (NAHUM, 2011, p. 68).

As configurações territoriais das redes hidrelétricas, de transportes, redes elétricas, de comunicação, rede urbana, consubstanciaram a condição essencial para a constituição de um processo de "modernização de superfície", contribuindo para a implantação de indústrias de grande porte no território paraense e no município de Barcarena (COELHO et al., 2004; MAIA, 2017).

Do ponto de vista das dinâmicas demográficas, segundo dados oficiais do Instituto Brasileiro de Geografia e Estatística (IBGE), do Censo Demográfico dos anos de 1970, o município de Barcarena apresentava $79,12 \%$ da população economicamente ativa do município ligada às atividades de agropecuária, extrativismo vegetal e pesca; $8,45 \%$ à atividade industrial e 12,43\% ao setor de serviços. Esses dados do Censo Demográfico nos levam a inferir que Barcarena era um município onde a economia estava atrelada predominantemente às dinâmicas do meio rural nos anos de 1970.

Do ponto de vista político, o leque de benefícios concedidos pelo Estado aos empreendedores do alumínio foi ampliado quando o projeto Albrás/Alunorte, que nasceu no âmbito do III Plano de Desenvolvimento da Amazônia - 1980-1985, passou, em 1981, a integrar o conjunto dos empreendimentos do Programa Grande Carajás - PGC, recebendo, assim, tratamento especial pelos órgãos e entidades da Administração Federal (LOBO, 1996).

As últimas décadas do século XX correspondem a momento de rápidas transformações no território do município de Barcarena, vinculadas aos novos nexos de modernização do território amazônico. A esse respeito, Rodrigues e Hazeu (2019) enfatizam que: 
|Jovenildo Cardoso Rodrigues | Rodrigo Luciano Macedo Machado | Luciano Rocha da Penha| |Adolfo Oliveira Neto |

O município de Barcarena está inscrito a todas essas mudanças globais, porém possuindo sua formação socioterritorial conformada por ribeirinhos, extrativistas, indígenas e quilombolas. Tal formação socioterritorial (de tradicionalidade) que fora invadido e reestruturado, principalmente na década de 1970 e 1980, por um complexo industrial-portuário ligado à transformação de bauxita em alumina e alumínio e a sua exportação.

O município com esse projeto portuário industrial e outras dinâmicas econômicas se insere como uma célula produtiva-especulativa e nó logístico dessa dinâmica de fluidez econômica e conexão com "cadeias de valor global", principalmente de commodities. E logicamente envoltos de processos dinamicamente interconectados e simultâneos, fortemente carregados de assimetrias de poder (COE; DICKEN; HESS, 2008) e "oligopólio de poder" por transnacionais e desigualdades sociais regionais e globais (PHILLIPS, 2017) (RODRIGUES; HAZEU, 2019, p. 820).

Rodrigues e Hazeu (2019) ajudam-nos a revelar um conjunto de transformações socioespaciais no referido município, decorrentes da territorialização de novos agentes econômicos vinculados a cadeias da produção industrial, logística e portuária, que atuam em escala global. A presença e ações de algumas empresas como Alunorte, Haidar, Minerva, e recentemente, a Imerys, vem contribuindo para desastres ambientais graves, com sérias consequências para comunidades rurais e urbanas do município de Barcarena (MAIA, 2017).

Tabela 01 - Ranking PIB a Preços Correntes - Pará e municípios - 2010 e 2015

Produto Interno Bruto a Preços Correntes (Mil Reais), Pará e municípios - 2010 e 2015

\begin{tabular}{lclc}
\hline \multicolumn{1}{c}{ Estado/Município } & $\mathbf{2 0 1 0}$ & \multicolumn{1}{c}{ Estado/Município } & $\mathbf{2 0 1 5}$ \\
\hline Pará & $\mathbf{8 2 . 6 8 4 . 5 1 8}$ & Pará & $\mathbf{1 3 0 . 8 8 3 . 4 2 6}$ \\
Belém & 18.801 .039 & Belém & 29.280 .972 \\
Parauapebas & 14.985 .170 & Parauapebas & 11.208 .942 \\
Ananindeua & 4.100 .513 & Marabá & 7.326 .872 \\
Marabá & 3.458 .625 & Ananindeua & 6.236 .496 \\
Tucuruí & 2.566 .105 & Barcarena & 5.520 .848 \\
Santarém & 2.309 .692 & Tucuruí & 4.235 .410 \\
Barcarena & 2.227 .150 & Santarém & 3.980 .291 \\
Canaã dos Carajás & 2.120 .092 & Canaã dos Carajás & 3.491 .231 \\
Castanhal & 1.738 .923 & Altamira & 3.220 .115 \\
Oriximiná & 1.635 .545 & Castanhal & 3.166 .661 \\
\hline
\end{tabular}

Fonte: FADESPA, 2018. Elaboração: MACHADO, R. L. M., 2020.

Do ponto de vista econômico, a Tabela 01, extraída a partir de dados da Fundação Amazônia de Amparo a Estudos e Pesquisas (FAPESPA), entre os anos de 2010 e 2016, permite afirmar que houve um crescimento de $\mathrm{R} \$ 3.293 .698$, ou seja, o município mais que duplicou o PIB, correspondendo também a 3,63\% do PIB estadual em 2016, sendo destaque nos últimos anos no cenário econômico estadual. 
| Interfaces do rural e do urbano na cidade de Barcarena, Amazônia paraense |

|Jovenildo Cardoso Rodrigues | Rodrigo Luciano Macedo Machado | Luciano Rocha da Penha| |Adolfo Oliveira Neto |

Figura 01 - Barcarena (PA): Mapa de localização de Barcarena e classificação de áreas rurais e urbanas, 2018

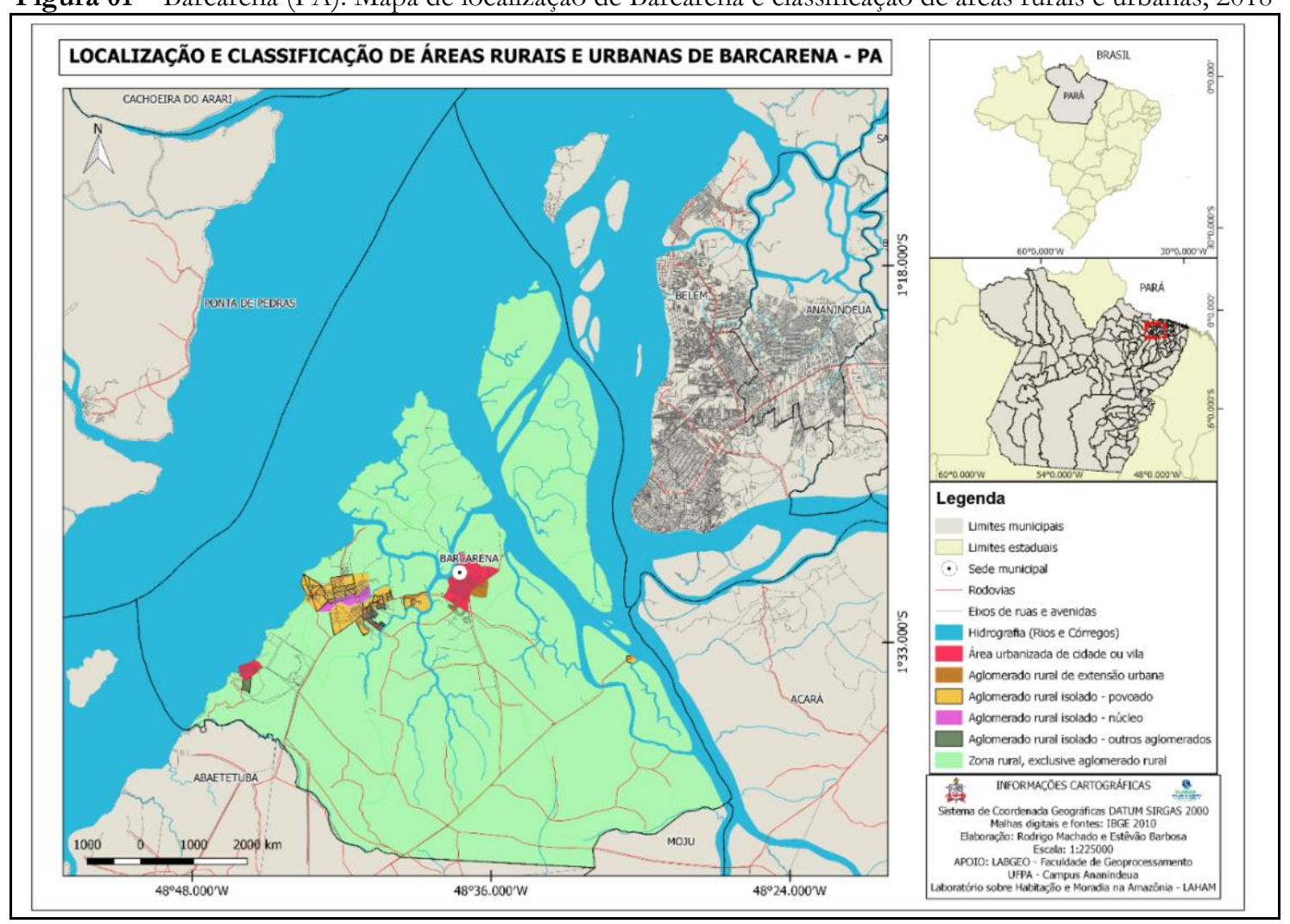

Fonte: Censo IBGE, 2010. Elaboração: MACHADO, R. L. M.; BARBOSA, E., 2020.

A Figura 01 (Mapa 01), concebida a partir de imagens de satélite, permite identificar o território municipal, bem como, as áreas rurais e urbanas de Barcarena. O Instituto Brasileiro de Geografia e Estatística (IBGE) considera as áreas pertencentes à Vila dos Cabanos e Vila do Conde como áreas de aglomerado rural isolado - povoado. Não obstante, há uma acentuada expansão urbana nas referidas áreas, com presença de novas ocupações e assentamentos urbanos, que não foram contempladas na análise deste Censo Demográfico de 2010.

Segundo o Plano Diretor de Desenvolvimento Urbano de Barcarena (PDDUB, 2016), o referido município possui dois distritos, quais sejam: 1) Barcarena Sede e 2) Distrito de Murucupi. No Distrito de Murucupi localizam-se a Vila Nova, Vila São Francisco e Vila dos Cabanos (ou Núcleo Vila dos Cabanos), e nos últimos anos surgiram novas ocupações como a do Pioneiro e Laranjal, ambas interligadas a Vila dos Cabanos, e tantas outras pequenas comunidades, além do complexo industrial. Algumas dessas comunidades possuem um importante destaque no processo de formação territorial de Barcarena:

A localização de São Francisco, uma das mais antigas encontra-se às margens do Rio Barcarena, tendo passado por um acelerado crescimento populacional desde a implementação do complexo industrial, atingindo um total de cerca de 1.500 habitantes em 1989. Essa localidade é habitada principalmente por pessoas de 
|Jovenildo Cardoso Rodrigues | Rodrigo Luciano Macedo Machado | Luciano Rocha da Penha| |Adolfo Oliveira Neto |

\begin{abstract}
baixas condições socioeconômicas. [...] Vila Nova situa-se à margem direita da baía do Marajó, próximo ao núcleo populacional de Itupanema, tendo surgido com o objetivo de proporcionar assentamento para famílias desprovidas de moradia em função das desapropriações implementadas pela Albrás/ Alunorte. [...]. Vila Itupanema, situada à margem direita da baia do Marajó é anterior a Albras/ Alunorte e nos primeiros anos de atividade industrial não sofreu incremento da população. Sua população é voltada para a caça, pesca, extrativismo vegetal e cultivos de pequenas lavouras de subsistência e itinerantes. Entretanto, nos últimos anos, a Vila de Itupanema vem apresentando um acelerado crescimento populacional promovido pelos constantes processos de ocupação espontâneas [...] (RODRIGUES, 2011, p. 7879).
\end{abstract}

Além das comunidades citadas acima, é importante ressaltar as dinâmicas históricogeográficas diferenciadas da Vila do Conde e Vila dos Cabanos. Vila do Conde tem sua origem no séc. XVII e até o início da década de 1970 era um pequeno lugarejo, habitado exclusivamente por lavradores e pescadores (RODRIGUES, 2011). A Figura 02 permite evidenciar que, a partir das instalações do complexo industrial, houve uma intensificação no crescimento desordenado na mancha urbana da cidade, atingindo a leste da Rodovia PA-483 e, ao sul, a margem direita do Igarapé Dendê (RODRIGUES, 2011).

Figura 02 - Marcha de expansão urbana no município de Barcarena

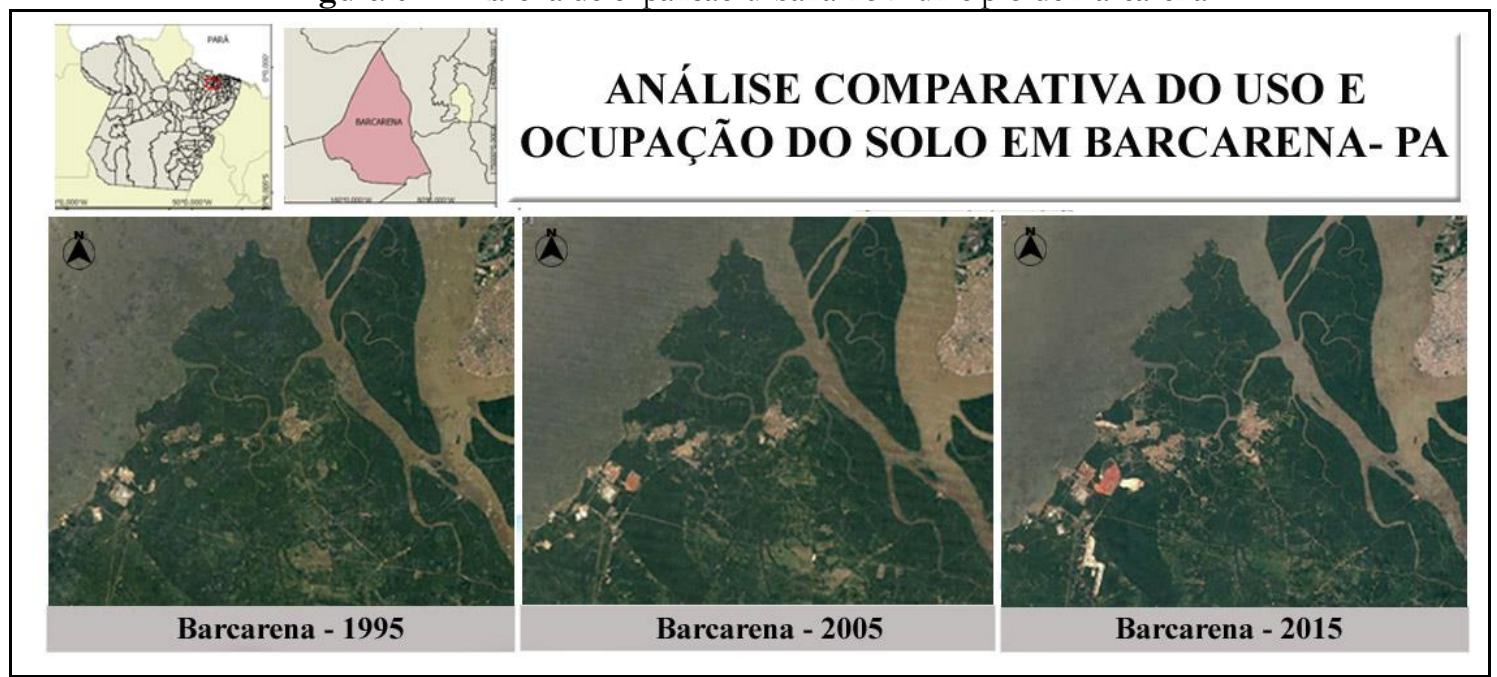

Fonte: Google Earth Pró, 2018.; IBGE, 2010. (Adaptado) Elaboração: MACHADO, R. L. M.; 2020.

A Figura 03 possibilita demonstrar que a população total do referido município teve crescimento demográfico de 499\% dos anos de 1980 para o ano de 2010. Tal crescimento encontra-se fortemente associado ao papel que as atividades industriais exercem na escala do território paraense. Há de se ressaltar, também, a condição de "cidade-porto" exercida por Barcarena, enquanto espaço de fluidez territorial e base-logística, a partir do qual ocorrem intensos fluxos de produtos como soja, alumínio, gado, para o mercado internacional (RODRIGUES; HAZEU, 2019). Os dados da Figura 03 permitem ilustrar também que, entre os anos de 1970 e 1980, ocorreu uma tendência de decréscimo da 
população rural, em cerca de $11 \%$, enquanto a população em áreas urbanas teve um aumento de quase $300 \%$.

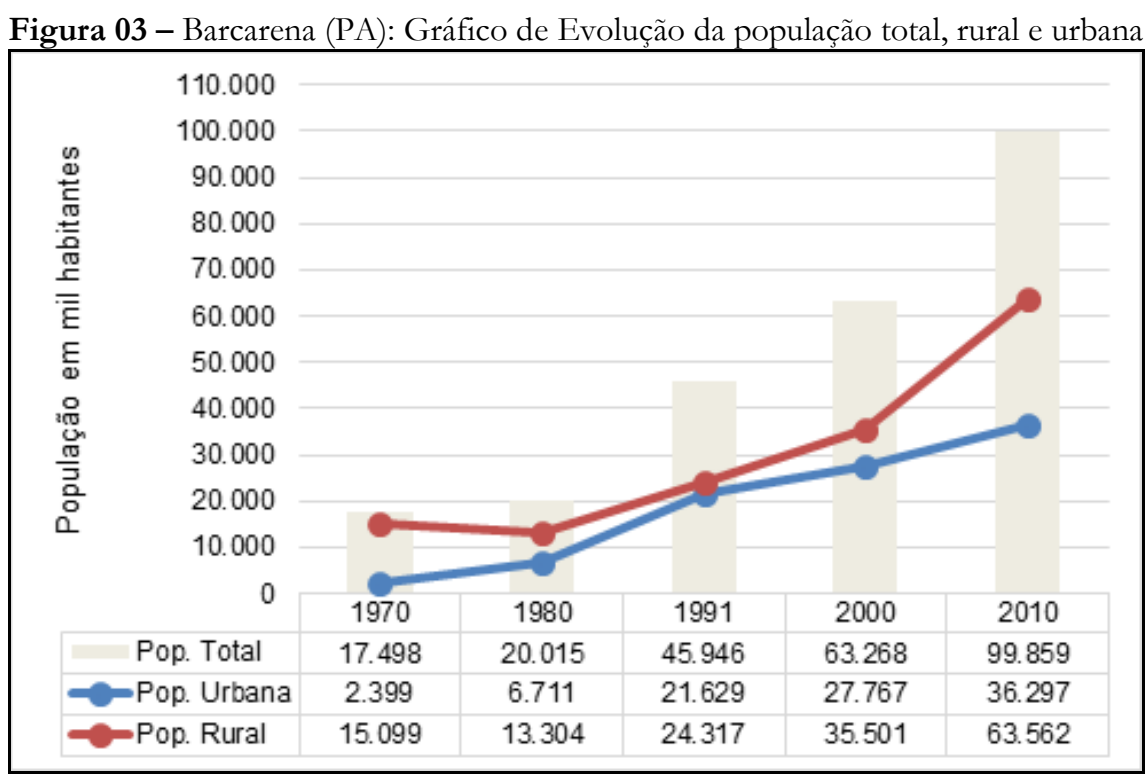

Fonte: IBGE - Censos Demográficos (1970, 1980, 1991, 2000 e 2010). Elaborado pelos autores.

De 1980 a 1991 há um nítido estreitamento e aproximação entre os índices populacionais rurais e urbanos, quando em 1991 a população rural retoma um crescimento, mas ainda representa $53 \%$ da população total e a população urbana cresce de forma mais acentuada e chega a quase metade da população total com 47\%. A partir dos dados do Censo Demográfico do IBGE dos anos de 2000, o distanciamento entre os dois índices populacionais é destacado, principalmente pelo maior crescimento do nível populacional rural em 2010, representando $64 \%$ contra 36\% da população urbana do referido município.

Podemos perceber uma brusca alteração no perfil socioeconômico e demográfico municipal de Barcarena a partir dos anos de 2000, com a presença e atuação de corporações transnacionais (Alunorte, Albrás, Pará Pigmentos, Imerys, Rio Capim Caulim) (SEPOF/IBGE, 2005). Nesse sentido, o setor industrial em Barcarena passou a responder a $70,59 \%$ da atividade econômica local, seguido por serviços $29,01 \%$ e por último a atividade agropecuária 0,40\% (SEPOF/IBGE, 2005). Considerando tais transformações sociais e econômicas, diversas comunidades rurais passaram a ter seus territórios fortemente impactados pelas atividades industriais e pela nova condição urbano-rural em Barcarena, qual seja, de territorialização do capital em ritmo acelerado, fato que tem resultado em processos de desterritorialização de comunidades, subsunção do trabalhador local a condições precárias impostas pela indústria, bem como, a desastres ambientais com sérias consequências para a população local. 
| Interfaces do rural e do urbano na cidade de Barcarena, Amazônia paraense |

|Jovenildo Cardoso Rodrigues | Rodrigo Luciano Macedo Machado | Luciano Rocha da Penha| |Adolfo Oliveira Neto |

A Figura 04 permite ilustrar uma característica peculiar deste município, posto que a população rural de Barcarena também é relevante do ponto de vista comparativo em uma análise estadual, ocupando a terceira colocação no ranking dos municípios paraenses com maior quantidade de habitação em área rural. Por sua vez, a Figura 05 possibilita inferir que o referido município encontra-se na sétima colocação no ranking dos municípios brasileiros com maiores quantitativos de habitantes domiciliados em área rural no país.

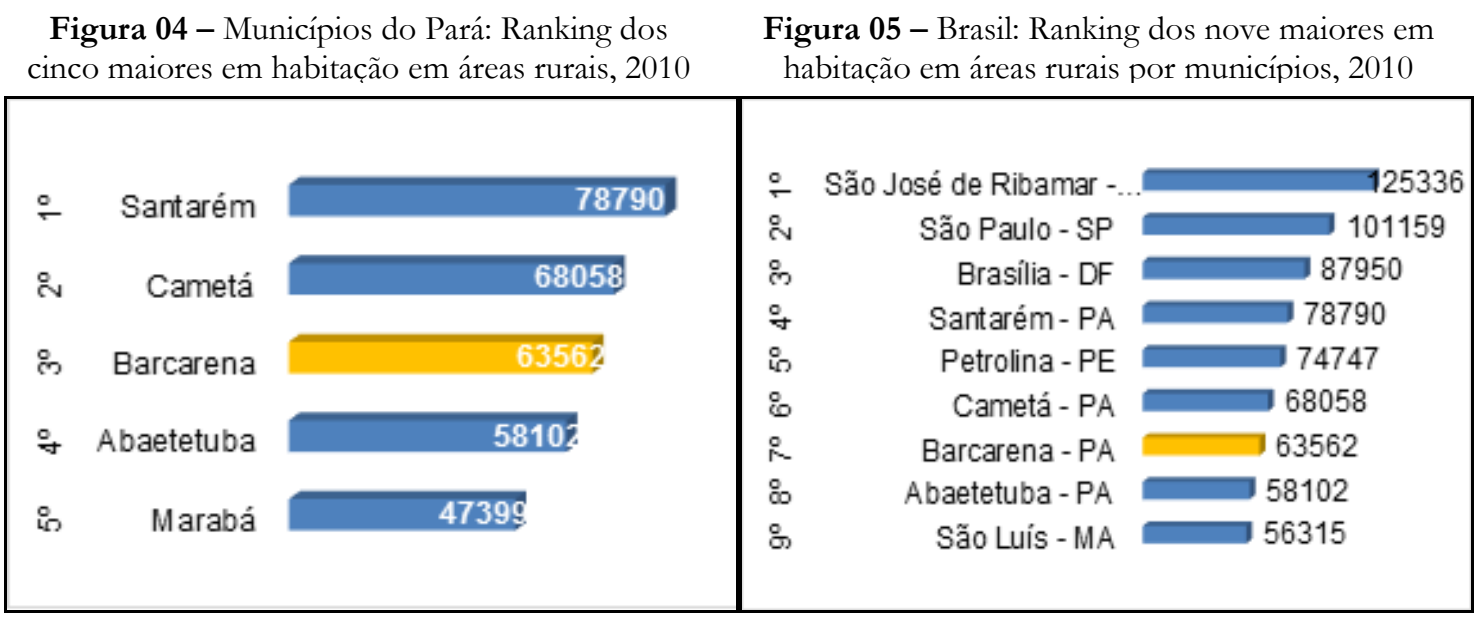

Fonte: IBGE, 2010. Elaborado pelos autores.

Fonte: IBGE, 2010. Elaborado pelos autores.

Com efeito, as características histórico-geográficas, bem como, as dinâmicas econômicas, sociais, demográficas permitem apreender que as transformações aceleradas no rural e no urbano em Barcarena implicaram apreender as sucessões e rupturas, continuidades e mudanças, as coexistências e resistências, cujas expressões revelam as interfaces e contradições nas relações rural-urbano em Barcarena.

\section{PERSPECTIVAS E INTERFACES DO RURAL E DO URBANO EM BARCARENA}

As espacialidades urbano-rurais em Barcarena impõem um desafio aos pesquisadores, no sentido de construir nexos explicativos para entender as recentes mutações nas relações rural-urbano em Barcarena. Diante de tal desafio, procuramos acionar duas estratégias metodológicas já anunciadas no início deste artigo, de maneira a auxiliar-nos na construção do processo de pesquisa, são elas: observações sistemáticas qualitativas e entrevistas semiestruturadas. A escolha de tais estratégias de pesquisa possibilitou-nos incorporar narrativas de representantes do poder público, de moradores, permitindo-nos capturar elementos da dimensão do cotidiano Barcarenense, para refletirmos analiticamente sobre as dinâmicas do rural e do urbano em Barcarena. 
| Interfaces do rural e do urbano na cidade de Barcarena, Amazônia paraense |

|Jovenildo Cardoso Rodrigues | Rodrigo Luciano Macedo Machado | Luciano Rocha da Penha| |Adolfo Oliveira Neto |

Em atividades de campo realizadas durante o ano de 2018, no município e na cidade de Barcarena, constatamos um mosaico de paisagens urbanas e rurais reveladoras de múltiplas e diversas relações, condições e contradições, bem como, dinâmicas socioeconômicas, diversidade populacional, estrutura municipal com forte destaque para a produção industrial, na Vila do Conde, intensa dinâmica ribeirinha, permitindo-nos entender o que Rodrigues, Sobreiro Filho e Oliveira Neto (2018) enfatizam como condição espacial nas relações do rural-urbano, quando se considera o urbano enquanto sociedade urbana em realização.

O núcleo urbano de Barcarena, também denominado Barcarena Sede, exerce um papel importante no contexto da microrregião do Baixo Amazonas, como "Cidade de Responsabilidade Territorial” (RODRIGUES; RODRIGUES, 2020) no que se refere ao atendimento de demandas por serviços públicos e privados (serviços bancários, serviços escolares, serviços hospitalares). A esse respeito, segundo o Senhor Luiz Guimarães, representante da Secretaria Municipal de Ordenamento Territorial e Habitação de Barcarena (SEMEOTH), a mesma foi criada com a finalidade de se estabelecer o "novo" para o município, que possuía a sua centralidade estabelecida no núcleo São Francisco.

O representante do poder público afirmou ainda que um dos grandes desafios da gestão se dará no sentido da regularização fundiária e da moradia, a partir de programas e parcerias nas esferas estaduais e federais, em face do crescimento demográfico acelerado a partir do início do século XXI. Acerca das dinâmicas urbanas na escala da cidade de Barcarena, o referido representante destaca:

[...] O que há em muitas localidades de Barcarena é um título de uso de superfície, e agora tudo isto está sendo organizado para termos dimensão do quantitativo de áreas já registradas e as que ainda precisam ser regularizadas. Barcarena sede possui hoje 855 residências, de acordo com o levantamento que estamos realizando. A secretaria atualmente faz um estudo detalhado acerca dos tipos de imóveis da sede municipal de Barcarena, com informações a serem disponibilizadas em breve, mas se nota que esta organização sócio-territorial é ainda muito complexa, em virtude das inúmeras alterações de fluxo, de tipologias residenciais, entre outras variáveis. Sobre as coletas de informações do IBGE no município, e identificação de áreas rurais e urbanas [...] há um fluxo de pessoas que está em trânsito no município, todos os dias uma movimentação constante, mas essas pessoas não têm casa, o censo não alcança essa parte da população. É uma população invisível, uma série de concentrações invisíveis (Entrevista realizada com Luiz Guimarães, técnico da SEMOTH, em 26 de dezembro de 2018).

Este relato reforça as divergências sobre os entendimentos acerca do que se entende por rural e o urbano, visto que os levantamentos recentes realizados pelo IBGE, Plano Diretor de Barcarena em 2016 e a partir do próprio relato de moradores, mostra um verdadeiro desafio para a elaboração de políticas públicas urbanas e rurais. Em primeiro 
|Jovenildo Cardoso Rodrigues | Rodrigo Luciano Macedo Machado | Luciano Rocha da Penha| |Adolfo Oliveira Neto |

plano, na esfera municipal existe um debate acerca da legitimidade das propriedades de terra, sobretudo em áreas rurais, como o representante da SEMOTH afirma:

A ideia de construir legitimidade, esse é o desafio, em 2016 o município já depois de um certo período tem uma nova redefinição territorial, ele cria o PDDU (Plano Diretor de Desenvolvimento urbano), então como ele é uma legislação, ele faz uma redefinição de urbanização do município. Você tinha áreas definidas como urbanas, até 2015, e que a partir desse plano de 2016 se redefiniu o que seria urbano e o que seria rural, pelo menos na legislação, por exemplo o Cafezal é considerado uma área rural, onde os moradores possuem título do ITERPA, órgão ligado ao INCRA [...] à medida que a cidade cresceu, com influência da ALBRÁS, essas áreas se tornaram bairros, mas ainda possuem título de terra de área rural, que está ligado ao ITERPA, e muitos desses indivíduos procuram a prefeitura para mudar a titulação para o município, passando a pagar o IPTU. Era um terreno supostamente grande, entretanto estas áreas foram vendidas, e eles procuram para pagar um valor de imposto da sua real área domiciliar. Esse desafio de transformar o que era rural para urbano é um processo que está ocorrendo agora a partir do PDDU. O município tem hoje áreas urbanas consolidadas, mas existem áreas de expansão urbana, são áreas que hoje são consideradas rurais na legislação e nas práticas do uso, mas já estão com previsão de crescimento na expansão da cidade, esses moradores em curto prazo deixarão de recolher imposto para o ITR rural, para o INCRA e para o ITERPA, e deverão ser cadastrados como moradores de áreas urbanas, pagando IPTU (Entrevista realizada com o representante da SEMOTH, em 26 de dezembro de 2018).

Já com base no PDDU do município existe outra interpretação no que concerne ao macrozoneamento rural e urbano, aparentemente mais próxima da realidade dos moradores de Barcarena, abrangendo uma maior parte do eixo de conexão dos núcleos urbanos, áreas industriais e comerciais. 
| Interfaces do rural e do urbano na cidade de Barcarena, Amazônia paraense |

|Jovenildo Cardoso Rodrigues | Rodrigo Luciano Macedo Machado | Luciano Rocha da Penha| | Adolfo Oliveira Neto |

Figura 06 - Barcarena (PA): Macrozoneamento Rural e Urbano, 2016

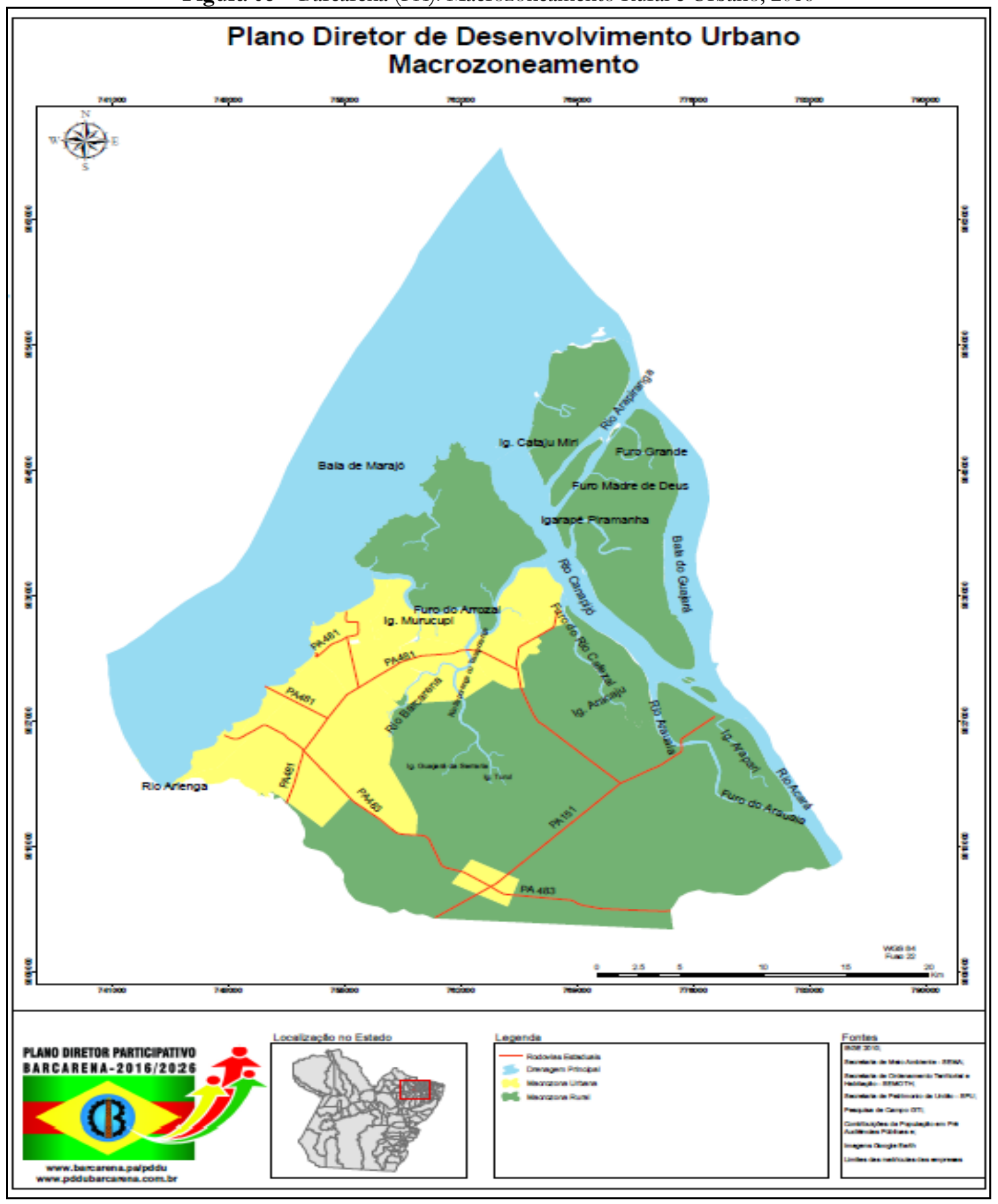

Fonte: PDDU, 2016.

A Figura 06 constitui imagem do macrozoneamento de Barcarena. O macrozoneamento tem o objetivo de definir diretrizes para orientar o desenvolvimento de acordo com as características físicas, sociais, culturais, econômicas e ambientais existentes no município (PDDU, 2016). A divisão ocorre em duas macrozonas: Macrozona Urbana MZU; Macrozona Rural - MZR. Ao se considerar que essas áreas, como a área territorial das ilhas do Arapari e Trambioca, e Vilas vêm sendo consideradas para efeito de ações públicas? 
| Interfaces do rural e do urbano na cidade de Barcarena, Amazônia paraense |

|Jovenildo Cardoso Rodrigues | Rodrigo Luciano Macedo Machado | Luciano Rocha da Penha| |Adolfo Oliveira Neto |

A Macrozona Rural compreende toda a área excedente do perímetro urbano, destinada prioritariamente às atividades agropecuárias, extrativistas, portuárias e industriais de baixo impacto ambiental. Considera-se área urbanizada aquela dotada de edificações e equipamentos públicos, obedecendo ao artigo 32 da Lei n 5.172, de outubro de 1966 Código Tributário Nacional (PDDU, 2016).

Existe uma clara definição por parte da gestão municipal a respeito do que se compreende por áreas rurais e urbanas, no entanto, como os moradores ressignificam o lugar onde vivem? Percebemos que há uma contradição entre as análises institucionais e as compreensões e representações dos moradores do lugar, no que concerne ao que se entende por urbano e rural em Barcarena.

Na comunidade Quilombola Santa Rosa, no bairro Laranjal, podemos identificar em entrevista com algumas moradoras uma divergência sobre a identificação de suas áreas, ao serem indagadas se aquela seria uma área rural ou urbana.

Entrevistador: Vocês consideram a comunidade uma área rural ou urbana?

Moradora 1 (44 anos): Pra mim, já é urbano, por causa da luz, das coisas que estão próximas.

Moradora 2 (32 anos): Pra mim, é rural, porque a gente aqui não tem benefícios, a gente ainda planta, a gente ainda pesca [...] nós sobrevivemos de pesca, plantação de mandioca, tudo isso a gente ainda faz, aqui a gente tem açaí [...]. O mesmo representante que leva as maquetes pra lá diz que aqui tá tudo bonitinho, e dizem que tá tudo asfaltado aqui, mas não está. Só é feito trabalho dali pra frente, aqui não entra [...] (Entrevista com moradoras da comunidade Santa Rosa, em 26 de dezembro de 2018).

Segundo as respectivas moradoras, o bairro Laranjal é constituído como uma das ocupações no entorno de Vila dos Cabanos. De acordo com Moura (1990), o Laranjal é um bairro do Núcleo urbano com uma área prevista inicialmente de 170 lotes e posteriormente ampliada para 344 lotes, localizada no bairro Pioneiro, que não constava no plano urbanístico, e foi organizado não só para assentar os desapropriados baixos, garantir nessa área uma população disponível como prestadora de serviços, mas como forma de recurso utilizado para, através da venda de lotes a preços mais às diversas demandas geradas pelo novo espaço social, não previsto no plano (MOURA, 1990).

A estrutura geralmente lembrada como rústica em áreas rurais, é ligeiramente encontrada na comunidade, entretanto, com nítidas modificações provenientes dos espaços urbanos, até mesmo na questão da ocupação dos moradores como ainda afirma uma das moradoras:

[...] Quem mais trabalha com negócio de roça é mais a minha mãe e o meu pai mesmo, e a gente ajuda né, assim meu pai pesca, mas não pesca aqui, pesca lá 
|Jovenildo Cardoso Rodrigues | Rodrigo Luciano Macedo Machado | Luciano Rocha da Penha| |Adolfo Oliveira Neto |

pra Vigia, Mosqueiro, pra lá que ele pesca. Aqui mesmo não presta pra pescar [...] (Entrevista realizada em 26 de dezembro de 2018).

As atividades industriais, de comércio e serviços aumentaram de maneira acelerada em Barcarena, contribuindo para a indução de dinâmicas demográficas e espaciais em direção à respectiva cidade, fato que vem repercutindo em aumento de assentamentos urbanos, além de conflitos pela posse da terra em espaços urbanos e rurais.

Em Vila Itupanema há uma dimensão singular desta dinâmica do rural e urbano. A esse respeito, a moradora 3 fala sobre o cotidiano das relações sociais e de trabalho, que ela e o marido levam no bairro

[...] Meu marido faz carvão para vender e é cabelereiro, e eu trabalho como manicure e a gente aqui em casa temos pupunheira, açaí, abacaxi e cupuaçu [...]. A gente se vira como dá, mas essa parte da roça é mais do meu sogro (Entrevista realizada em 27 de dezembro de 2018).

Nesta localidade podemos observar a dualidade de funções que os moradores possuem, não sendo vistos apenas como agricultores, mas já possuem práticas ligadas ao domínio urbano, principalmente atividades voltadas ao trabalho informal (Figura 07), como forma de sobrevivência e adaptação ao modo de vida urbano (Figura 08) e interações ruralurbano, que cada vez mais se estreitam à medida que novos modos de vida vão sendo impostos pelo capitalismo, que acompanha esta dinâmica de reconfiguração da cidade. As Figuras 07 e 08 permitem ilustrar o rural-urbano em Barcarena, enquanto processos dialéticos e contraditórios revelados pelas dinâmicas urbano-rurais de trocas econômicas, denotando uma perspectiva de informalidade e precariedade nos modos de vida. Tal constatação empírica assemelha-se as reflexões de Rodrigues, Sobreiro Filho, Oliveira Neto (2018), para quem o rural-urbano necessita ser compreendido enquanto contradição.

Figura 07 - Vila Itupanema, Barcarena (PA): Informalidade e novas alternativas em áreas rurais, 2018

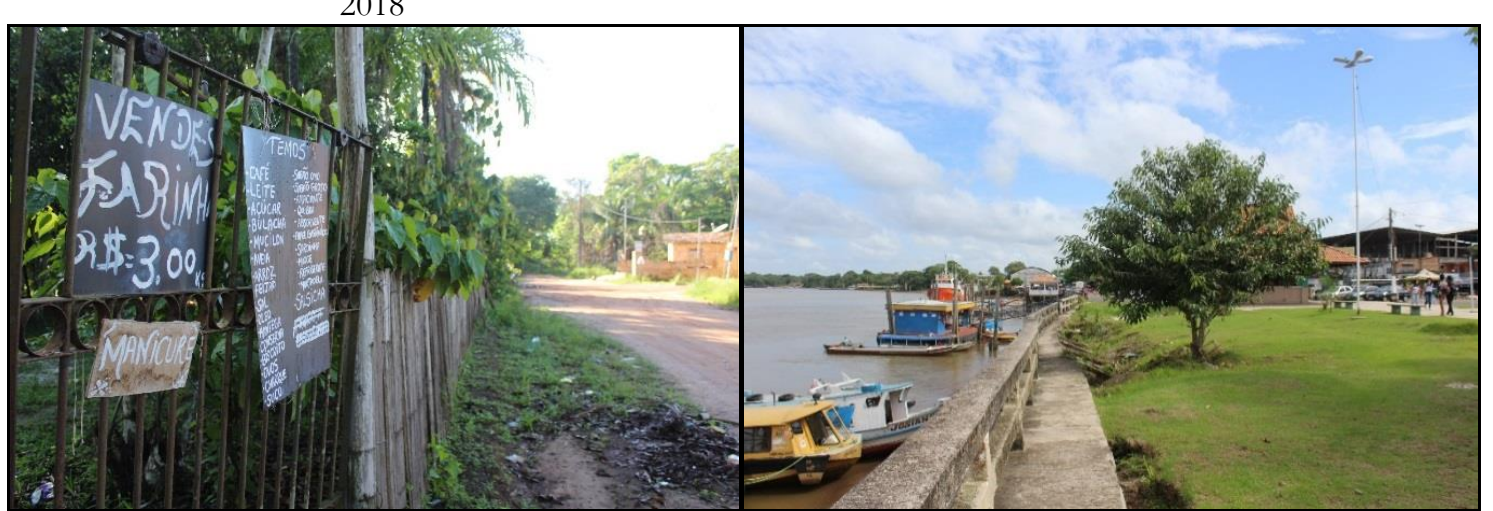

Fonte: Atividade de campo em Barcarena (PA), realizada em 27 de dezembro de 2018. Acervo dos autores.
Figura 08 - Barcarena sede, Barcarena (PA): Interações e fluxos de atividades econômicas, 2018 
| Interfaces do rural e do urbano na cidade de Barcarena, Amazônia paraense |

|Jovenildo Cardoso Rodrigues | Luciano Rocha da Penha | Rodrigo Luciano Macedo Machado | |Adolfo Oliveira Neto |

É importante ressaltar a interferência da indústria nessas áreas. Neste sentido, Vila Itupanema fica em uma das áreas mais próximas da Hydro/Alunorte e Imerys, resultando em queixas por parte dos agricultores, por não conseguirem produzir como em períodos anteriores, por conta do solo e terrenos devastados. Há que se ressaltar a existência de conflitos territoriais entre agricultores e as respectivas empresas. Muitos sobrevivem da coleta de frutos, e com apoio de alguns programas, existem produtores rurais que possuem cadastros em áreas rurais, mas moram em áreas urbanas, e o que se notou, de acordo com entrevistas, é que muitas vezes estes produtores utilizam este artifício para suprir interesses pessoais. Como destaca o Dr. Luiz Guimarães:

[...] A ideia que a gente tem, é que eles estão totalmente conectados ás áreas. O indivíduo que se cadastra nessas áreas rurais possui vínculo nessas áreas urbanas, com práticas de lazer, por exemplo [...]. As terminologias do rural e urbano aqui são abstratas, quando não se tem um movimento estático, é muito difícil fazer uma barreira e dizer: quem mora daqui pra cá é rural e daqui pra lá é urbano. Porque, mesmo nessas condições os indivíduos se movem, eles se intercambiam, por causa das escolas, por causa dos negócios que se tem, eles possuem a sua vivência lá, mas todo o negócio dele está aqui na cidade, apesar dessas fronteiras que a gente tende a construir [...] (Entrevista realizada com um membro da SEMOTH, em 26 de dezembro de 2018).

As práticas urbanas e rurais passam por transformações contínuas, com contribuição de inúmeras interferências promovidas pelas ações econômicas e do Estado. É interessante observar a contradição de um espaço delimitado por vias urbanas, mas que se misturam a práticas que lembram o aspecto rural (Figura 09), em meio aos principais núcleos urbanos de Barcarena, mostrando que estas relações se aproximam de uma forma peculiar e de amplas dimensões. Esta é uma contínua contradição, presente nos modos de vida, no movimento que destrói e recria hábitos, incorpora e expulsa pessoas, transforma e conserva coisas, fatos e costumes, este processo de expansão incorpora os espaços rurais sem, contudo, torná-los urbano, mas apropria-se de suas peculiaridades, ajustando as suas finalidades (BAGLI, 2006). 

| Adolfo Oliveira Neto |

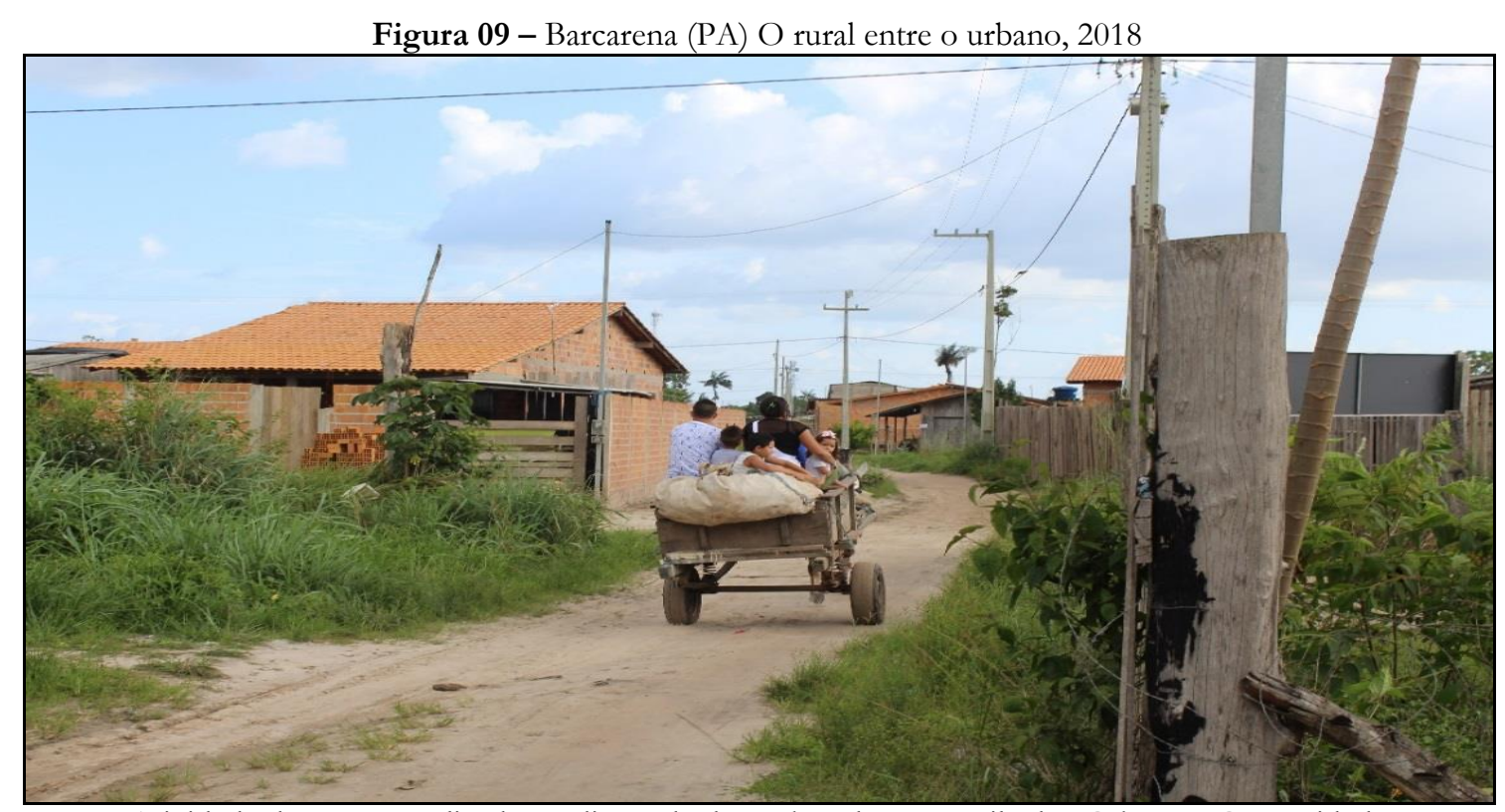

Fonte: Atividade de campo realizada no dia 26 de dezembro de 2018; Vila dos Cabanos, Comunidade Nossa Senhora de Fátima. Acervo dos autores.

A Figura 09 permite ilustrar a presença de uma família conduzindo uma carroça em chão de terra-batida, adentrando na Comunidade Nossa Senhora de Fátima, considerada área rural pelo poder público, mas que possui postes de energia elétrica, casas em alvenaria, permitindo perceber um mosaico de espacialidades urbano-rurais que se encontram imbricadas e sobrepostas revelando as condições de vulnerabilidade e desigualdade socioespacial, característica marcante dos espaço urbano-rurais das cidades amazônicas.

\section{CONSIDERAÇÕES FINAIS}

As duas primeiras décadas do século XXI correspondem a momentos marcados por rápidas e sucessivas transformações no território do município e da cidade de Barcarena, vinculadas a ordenamentos territoriais federais, estaduais e municipais, a territorialização do capital, bem como, a dinâmicas sociais, econômicas e espaciais associadas à produção do espaço urbano e rural na referida cidade.

Nestas circunstâncias histórico-geográficas, pensar a cidade de Barcarena requer a apreensão do rural e do urbano não exclusivamente como sinônimo de concentração demográfica, mas como ruralidades e urbanidades amalgamadas em feixes de relações expressos nas dinâmicas ribeirinhas, no movimento das feiras livres, nos modos de vida, nas resistências cotidianas dos moradores das áreas rurais diante da condição de desigualdade e vulnerabilidades socioespaciais.

A condição espacial desta cidade como caleidoscópio de múltiplas paisagens urbanas sobrepostas, imbricadas, conformando rugosidades do tradicional e do moderno, 
| Interfaces do rural e do urbano na cidade de Barcarena, Amazônia paraense |

|Jovenildo Cardoso Rodrigues | Rodrigo Luciano Macedo Machado | Luciano Rocha da Penha| |Adolfo Oliveira Neto |

de tempos e ritmos, de mudanças e permanências, expressam dinâmicas espaciais nas quais o rural e o urbano realizam-se enquanto pares dialéticos e processos que se transmutam permanentemente, como resultado de dinâmicas sociais da produção do espaço urbanorural em um contexto marcado pela forte territorialização de agentes econômicos de capital internacional na escala da cidade.

As novas dinâmicas globais vinculadas a indução de processos industriais na escala da cidade e no campo em Barcarena, ao mesmo tempo em dinamizam economicamente o território da cidade, trazem consigo, os efeitos territoriais vinculados ao processo de territorialização do capital como: indução de fluxos demográficos acelerados para o município, ampliação de déficit habitacional, desterritorialização de comunidades tradicionais nas áreas rurais de Barcarena, conflitualidades relacionadas a perda de territórios por parte de comunidades quilombolas, ribeirinhos, agroextrativistas.

Dessa maneira, a "cidade ribeirinha" coexiste com a "cidade-porto", com a "cidadeindústria", revelando relações, condições espaciais e contradições do rural-urbano em Barcarena, seja a partir da sociabilidade do homem simples, que sobrevive e se reproduz precariamente no espaço periurbano de Barcarena, seja nas habitações precárias, nas condições de infraestrutura urbana insuficientes ou inexistentes na escala municipal, demandando uma agenda de pesquisa que permita investigar as novas mutações da produção capitalista do espaço e suas implicações na produção dos territórios urbano-rurais de Barcarena.

Com efeito, o rural-urbano para além de conceitos constituem processos dialéticos que necessitam ser apreendidos e redefinidos, considerando a singularidade e demandas sociais dos territórios desta cidade paraense, enquanto possibilidade para subsidiar ações públicas na construção de políticas urbano-rurais inclusivas e democráticas, que permitam promover justiça espacial e qualidade de vida aos cidadãos barcarenenses.

\section{REFERÊNCIAS}

BAGLI, P. Rural e urbano: harmonia e conflito na cadência da contradição. In: SPOSITO, M. E. B.; WHITAKER, A. M. (Org.). Cidade e campo: relações e contradições entre o urbano e o rural. São Paulo: Expressão Popular, 2006. p. 81-110.

CARLOS, A. F. A. A Cidade. 7. ed. São Paulo: Contexto, 2013.

COELHO, M. C. N.; MONTEIRO, M. A.; SANTOS, I. C. Políticas públicas, corredores de exportação, modernização portuária, industrialização e impactos territoriais e ambientais no município de Barcarena, Pará. Novos Cadernos NAEA, Belém, v. 11, n. 01, p. 141-178, 2004. 
| Interfaces do rural e do urbano na cidade de Barcarena, Amazônia paraense |

|Jovenildo Cardoso Rodrigues | Rodrigo Luciano Macedo Machado | Luciano Rocha da Penha| | Adolfo Oliveira Neto |

Disponível em: <https://periodicos.ufpa.br/index.php/ncn/article/view/264/412>. Acesso em: 22 jun. 2019.

IBGE. Censo Demográfico 1970. Rio de Janeiro: IBGE, 1970.

. Censo Demográfico 1980. Rio de Janeiro: IBGE, 1980.

. Censo Demográfico 1991. Rio de Janeiro: IBGE, 1991.

. Censo Demográfico 2000. Rio de Janeiro: IBGE, 2000.

. Censo Demográfico 2010. Rio de Janeiro: IBGE, 2010.

KIELING, R. I.; SILVEIRA, R. L. L. O rural, o urbano e o continnum urbano-rural no contexto do desenvolvimento regional. Revista Perspectiva, Erechim, v. 39, n. 148, p. 133 143, dez. 2015.2 Disponível em: < http://www.uricer.edu.br/site/pdfs/perspectiva/148 540.pdf> $>$. Acesso em: 22 jun. 2019.

LEFEBVRE, H. De lo rural a lo urbano. 3. ed. Barcelona: Ediciones Peninsula, 1969.

LENCIONI, S. Observações sobre os conceitos de cidade e urbano. GEOUSP - Espaço e Tempo, São Paulo, v. 12, n. 01, p. 109-123, abr. 2008. Disponível em: $<$ https://www.revistas.usp.br/geousp/article/view/74098/77740>. Acesso em: 24 jun. 2019.

LOBO, M. A. A. Estado e Capital Transnacional na Amazônia: o caso da AlbrásAlunorte. Belém: UFPA/NAEA, 1996.

MAIA, R. O. M. Territorialidades específicas em Barcarena confrontadas com projetos de “desenvolvimento". 2017. 321 f. Tese (Doutorado em Desenvolvimento Socioambiental) - Núcleo de Altos Estudos Amazônicos, Universidade Federal do Pará, Belém, 2017. Disponível em: <http://repositorio.ufpa.br/jspui/handle/2011/9062>. Acesso em: 20 jun. 2019.

MONTE-MÓR, R. L. M. O que é o urbano, no mundo contemporâneo. Belo Horizonte: UFMG/Cedeplar, 2006.

MOURA, E. A. F. Laranjal sem laranjas: condições de vida após a implantação dos grandes projetos na Amazônia. VII Encontro Nacional da ABEP, 7., 1990, São Paulo. Anais eletrônicos... São Paulo: ABEP, 1990. Disponível em: $<$ http://www.abep.org.br/publicacoes/index.php/anais/article/view/549/529\#>. Acesso em: 15 jun. 2019.

NAHUM, J. S. Usos do território, modernização e ações políticas conservadoras em BarcarenaPA. Geosul, Florianópolis, v. 23, n. 45, p 65-84, jan./jun. 2008. Disponível em: $<$ https://periodicos.ufsc.br/index.php/geosul/article/view/2177-5230.2008v23n45p65>.

Acesso em: 25 jun. 2019.

PORTO-GONÇALVES, C. W. Amazônia: encruzilhada civilizatória: tensões territoriais em curso. Rio de Janeiro: Consequência Editora, 2017. 
|Jovenildo Cardoso Rodrigues | Rodrigo Luciano Macedo Machado | Luciano Rocha da Penha| |Adolfo Oliveira Neto |

PREFEITURA MUNICIPAL DE BARCARENA, Plano Diretor de Desenvolvimento Urbano (PDDU). $2016 . \quad$ Disponível em: $<\underline{\text { http://www.barcarena.pa.gov.br/portal/site?tipo=servico empresa\&am\&id=20\&nome }}$ =PDDU > . Acesso em: 19 maio 2020.

RODRIGUES, J. C.; HAZEU, M. T. Projetos de infraestrutura, desastres e indicativos para novos desastres em Barcarena, Pará, Brasil. DRd - Desenvolvimento Regional em debate, Canoinhas/Santa Catarina, v. 09, p. 818-838, 2019. Disponível em: $<$ https://www.periodicos.unc.br/index.php/drd/article/view/2457>. Acesso em: 25 maio 2019.

- (Re)estruturação da cidade e as novas expressões de centralidade urbana na cidade de Ananindeua, Amazônia paraense. Caminhos de Geografia, Uberlândia, 2020. (No prelo).

; SOBREIRO FILHO, J.; OLIVEIRA NETO, A. O rural e o urbano na Amazônia metropolitana: reflexões a partir de Ananindeua, Pará. Revista NERA, Belém, v. 21, n. 42, p. 256-280, 2018.

RODRIGUES, J. E. C. Ocupação e uso da terra como indicador de risco ambiental nos distritos de Murucupi e Vila do Conde, município de Barcarena-PA. In: NAHUM, J. S. (Org.). Dinâmicas territoriais e políticas no município de Barcarena no estado do Pará. Belém: Editora Açai, 2011. p. 71-104.

SPOSITO, M. E. B. Capitalismo e Urbanização. Contexto, 2004

\section{Como citar este artigo:}

\section{ABNT}

RODRIGUES, J. C.; MACHADO, R. L. M.; PENHA, L. R. da; OLIVEIRA NETO, A. Interfaces do rural e do urbano na cidade de Barcarena, Amazônia paraense. InterEspaço: Revista de Geografia e Interdisciplinaridade, v. 6, e202016, 2020. Disponível em: <http://dx.doi.org/10.18764/2446-6549.e202016>. Acesso em: 25 jan. 2020.

\section{APA:}

Rodrigues, J. C., Machado, R. L. M., Penha, L. R. da, \& Oliveira Neto, A. Interfaces do rural e do urbano na cidade de Barcarena, Amazônia paraense. InterEspaço: Revista de Geografia e Interdisciplinaridade, v. 6, e202016. Recuperado em 25 janeiro, 2020, de http://dx.doi.org/10.18764/2446-6549.e202016

\section{@creative}

This is an open access article under the CC BY Creative Commons 4.0 license.

Copyright (C) 2020, Universidade Federal do Maranhão.

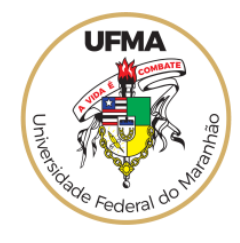

